\title{
Investigation of passive porosity as a means for bluff-body drag reduction
}

\author{
Alvin Gatto \\ Brunel University \\ Holger Babinsky \\ Cambridge University
}

\begin{abstract}
An investigation into the capability of passive porosity to reduce the drag of a bluff-body is presented. This initial work involves integrating varying degrees of porosity into the side and back faces of a small-scale model to determine optimum conditions for maximum drag reduction. Both force and pressure measurements at differing degrees of model yaw are presented, with the conditions for optimum performance, identified. At a length-based Reynolds number of $2.3 \times 10^{6}$, results showed a maximum drag reduction of $12 \%$ at zero yaw when the ratio of the open area on the back face relative to the side faces was between two and four. For all non-zero yaw angles tested, this ratio reduced to approximately two, with the drag benefit reducing to $6 \%$ at 10.5 degrees. From a supplementary theoretical analysis, calculated optimum bleed rate into the base for maximum drag reduction, also showed reasonable agreement to other results reported previously.
\end{abstract}

\section{Introduction}

Passive porosity has been investigated for a wide variety of applications to improve aerodynamic performance. As a means for allowing passive 'communication' of high and low pressure areas on a body via an internal plenum chamber, the fundamental physics underlying this technique are generally well understood. From the mitigation of asymmetric loading on bodies of revolution[1,2], shock wave suppression[3], or as an alternative means for aircraft control[4,5], this technique continues to be popular within the engineering and scientific community.

Another well suited but somewhat under-explored use of passive porosity is low speed bluff-body drag reduction. For this specific case, the technique appears ideal, with the flow characterized by a low pressure trailing wake, and sufficient body volume to facilitate 'communication' to higher pressure regions. Frink et al[6] was one of the first to consider this application with a focus on heavy goods vehicle drag reduction. Using a $1 / 12^{\text {th }}$-scale, rectangular model (quarter circle rounded cab) with $30 \%$ porous ${ }^{1}$ sides, top and back faces, several different porosity configurations, at differing Mach numbers, were investigated. With a porous back face(22\%), and 5\% (of model length upstream from the base) porous top, and sides(equivalent porosity of $\approx 1.5 \%$ ), up to an $11 \%$ drag reduction was measured. Computational results indicated similar benefits, although at much lower absolute drag levels $(\approx 17 \%)$ compared to experiments. This discrepancy was thought related to the apparent disappearance of the computed wake. Qualitatively, a smaller wake influence was also inferred at full-scale, with a noticeable reduction in rear spray in wet conditions.

Wood[7], and Bauer and Wood[8], also outline the use of passive porosity for a similar application. Using a porous cover similar to Frink et al[6] or through perforating existing surfaces, hole diameters of up to $6.3 \mathrm{~mm}$ on the sides, and $12.7 \mathrm{~mm}$ on the back, at porosity levels up to $20 \%$, are suggested as possible limits for best use. Wood and Bauer[5] also note several instances of best design practice for application to control effectors. These include using porous hole diameters less than the boundary layer thickness, and both a plenum chamber depth, and surface thickness, at least twice porous hole diameter. While relevant for this application, it remains unclear if many of these criteria apply as well to the low-speed, bluff-body flow case, aligned more with vehicle applications. This is particularly pertinent under misaligned flow conditions, with the influence of such changes remaining largely unreported.

The current study seeks to resolve some of these issues by undertaking an investigation into the optimal use of passive porosity as a means for bluff-body drag reduction. As the influence of flow misalignment on bluff-bodies similar in shape to large vehicles is yet to be reported, this will be one focus of the work. Porosity level, and different hole diameters, are also considered, with final assessments made in terms of internal plenum pressure, measured drag force, and comparisons to data from similar configurations[9-11].

\section{The Passive Porosity Concept}

Figure 1 shows a plan view schematic of the passive porosity concept applied to a generic bluff-body configuration. Immersed within a flowfield, the model contains porous sides and back faces connected via an internal plenum chamber. As a result of the lower base pressure within the wake, 'communication' through the back face porosity to the higher plenum pressure, $\mathrm{P}$, is allowed, stimulating transpiration flow. With the same mechanism existing between the near constant plenum pressure $\mathrm{P}$, and the higher relative pressure acting on the sides, $\mathrm{P}_{\infty}$, a condition where $\mathrm{P}_{b}<\mathrm{P}<\mathrm{P}_{\infty}$ exists. In each transition, mass flux is transferred from one region to the other; however, overall, zero net mass flux is added.

\footnotetext{
${ }^{1}$ Ratio of open to closed surface area
}

Page 1 of 7 


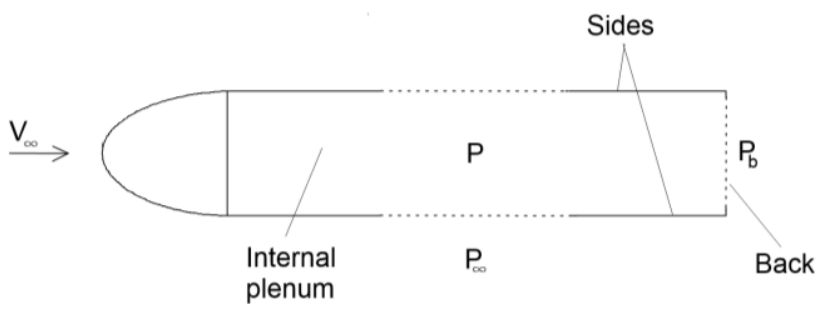

Figure 1. Passive porosity concept for bluff-body drag reduction.

For the application as shown in Figure 1, the concept requires two pressure differentials, $\Delta \mathrm{P}_{\mathrm{s}}$, and $\Delta \mathrm{P}_{\mathrm{B}}$ to generate each transpiration flow. In each transition, the flow negotiates body faces that contain a number of holes (Ns, NB) of individual diameter ( $\left.\mathrm{Ds}_{\mathrm{s}} \mathrm{D}_{\mathrm{B}}\right)$. The pressure differentials are defined here as;

$$
\begin{aligned}
\Delta P_{S} & =P_{\infty}-P \\
\Delta P_{B} & =P-P_{b}
\end{aligned}
$$

For each transition, the transpiration flow can be modelled many ways. Kraushaar and Chokani[12] summarize and asses some of these methods including the Darcy-constant, Darcy-sinusoidal, Darcy-geometric, and non-linear 'pipe-flow' models. Considering all models, the Darcy-constant and Darcy-sinusoidal are considered overly simplistic; both use linear relationships between transpiration velocity and differential pressure. They also ignore important additional flow influences such as hole diameter and plate thickness, and are therefore, not considered here. Both the Darcy-geometric and non-linear 'pipe-flow' models account for these deficiencies, with the non-linear pipe-flow theory[13] giving more consistent results under the conditions specified. Only this model, represented by Equations 3-5, will be adopted here.

$$
\begin{gathered}
Y=40.76 X+1.962 X^{2} \\
X=\frac{\pi \rho D^{2}}{4 \mu L} v \\
Y=\frac{\rho D^{4}}{(\mu L)^{2}} \Delta P+\frac{1}{2}\left(\frac{\rho D^{2}}{\mu L} v\right)^{2}
\end{gathered}
$$

This theory relates the transpiration flow through a porous surface as a non-linear function of the differential pressure using two characteristic variables (in this case $\mathrm{X}$ and $\mathrm{Y}$ ). Assuming conservation of volume fluxes and incompressible flow, transpiration velocities for each transition can be deduced using Equations 3-5 and the conservation of mass relationship;

$$
Q=(O A S) v_{S}=(O A B) v_{B}
$$

Where OAS and OAB are the open area of the side(both), and back faces respectively, given by;

$$
\begin{gathered}
O A S=N_{S} \pi \frac{\left(D_{S}\right)^{2}}{4} \\
O A B=N_{B} \pi \frac{\left(D_{B}\right)^{2}}{4}
\end{gathered}
$$

As can be seen in Equation 6, an expression for the ratio of transpiration velocities can be given through the introduction of an Open Area Ratio(OAR), given by Equation 9;

$$
O A R=\frac{O A B}{O A S}=\frac{v_{S}}{v_{B}}
$$

\section{Experimental Setup and Apparatus}

\section{The Test Model}

The baseline model used for all testing is shown in Figure 2. Measuring 750x150x150mm in overall length, width, and height, a square cross-section, rectangular body, with streamlined (2:1 elliptical profile) front nose, is used. This design was chosen to generate, at small-scale, the general flow characteristics of a large bluff-body vehicle(streamlined front and large separated wake). The model was constructed from machined RAKU-TOOL $\odot$ [14] modelling board and clear Perspex[15] sheet, with a large empty volume available for use as both a plenum chamber, as well as to take internal pressure measurements, using a pressure meter.

To incorporate passive porosity within the model, rectangular arrays of differing diameter holes where manufactured into the sides and back of the model. For each side face, a fixed rectangular array of 60 x 24 holes is used, with an unchanged 27 x 26 hole array for the back face. This gives a ratio of $\mathrm{N}_{\mathrm{S}} / \mathrm{N}_{\mathrm{B}}=4.1$, with a standard, $5 \mathrm{~mm}$ array spacing between holes, adopted(see Figure 2 - Details A-C). For each face, hole arrays were positioned near the geometric center of each surface, with a total of four different hole diameters for both Ds, and $\mathrm{D}_{\mathrm{B}}$, considered (1mm, $\left.2 \mathrm{~mm}, 3 \mathrm{~mm}, 4 \mathrm{~mm}\right)$. To establish a baseline, 'closed' configurations were tested by covering all holes from the inside with adhesive tape.

In order to ensure turbulent boundary layer conditions over the rear section of the model, the elliptical front nose of the model was left purposely rough to promote early transition to turbulence within the boundary layer. Measurements of the nose surface finish with a roughness meter confirmed a comparable surface roughness to 240grit Emery paper. Based on criteria specified in Schlichting and Gersten[16], this was deemed sufficient to ensure representative behavior.

Page 2 of 7 


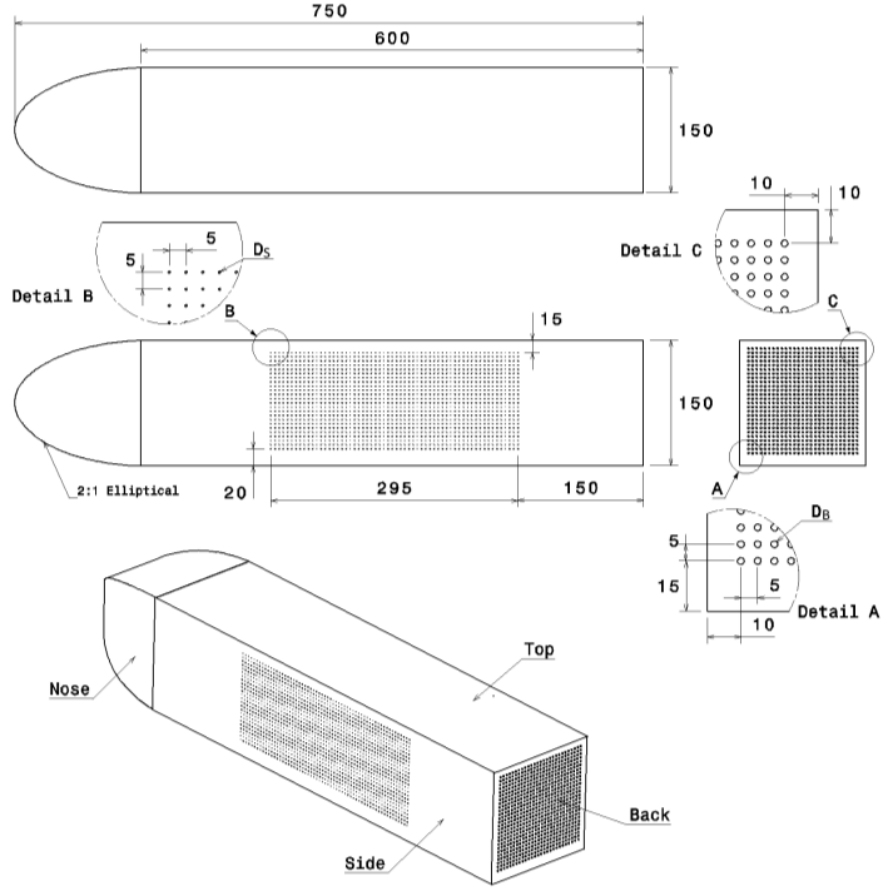

Figure 2. Schematic of wind tunnel test model with integrated passive porosity. $\mathrm{w}=\mathrm{h}=150 \mathrm{~mm}, \mathrm{~b}=600 \mathrm{~mm}, \mathrm{l}=750 \mathrm{~mm}$. All dimensions in $\mathrm{mm}$.

\section{The Wind Tunnel Setup and Instrumentation}

The Markham wind tunnel[17] at the University of Cambridge was used for all testing. A closed-test-section, closed-circuit configuration, the maximum achievable flow velocity inside the 1.68 $\times 1.22 \mathrm{~m}$ test-section is $60 \mathrm{~m} / \mathrm{s}$. Mounted at the center of the test section volume, maximum model blockage, based on frontal area at maximum yaw, was less than $2.1 \%$. No subsequent blockage corrections were applied. Turbulence intensity at model station was rated at $0.2 \%$, with the operating flow speed for this investigation set at $45 \mathrm{~m} / \mathrm{s}$. Based on model length, these test conditions gave a Reynolds number of $\operatorname{Re}_{\mathrm{n}}=2.3 \times 10^{6}\left(\operatorname{Re}_{\mathrm{n}}=4.6 \times 10^{5}\right.$ based on model width).

The model was mounted on a streamlined support strut (Figure 3) affixed to an aluminum floor insert installed within the tunnel floor. Between the model support strut and the floor insert, a load cell was positioned allowing all six forces and moments acting on the model to be measured. An in-built articulated adjustment mechanism also allowed changes in yaw angle to assess this influence. To ensure minimal aerodynamic disturbance between the support strut and the floor insert, a two-piece, flat plate aluminum cover, was placed around the strut with a nominal $5 \mathrm{~mm}$ gap. This allowed sufficient, unhindered, support strut deflection under aerodynamic loading, as well as, minimal external air ingress inside the tunnel. No ground board, simulating the influence of ground-effect, is used.

The six axis force and moment balance used for all testing is an AMTI MC3A-500[18]. The maximum lift, drag and side force capabilities, of the cell were $\pm 2 \mathrm{kN}, \pm 1 \mathrm{kN}$, and $\pm 1 \mathrm{kN}$ respectively, with the maximum range for pitching, rolling, and yawing moments, being $\pm 56 \mathrm{Nm}, \pm 56 \mathrm{Nm}$, and $\pm 28 \mathrm{Nm}$. During initial testing, individually optimized measurement ranges were configured for all six-axes using a DigiAmp[19] strain gauge amplifier. This procedure maximized the possibility for best data integrity. After a subsequent calibration, maximum deviations for any of the six axes were found to be less than $\pm 2.5 \%$ within a $95 \%$ confidence interval $\left(\Delta C_{D}=\right.$ $\pm 0.02)$.

To measure the internal plenum pressure of the model under differing flow conditions, a Digitron 2081P differential pressure meter[20] was installed inside the empty volume of the model(influence of changing volume not considered). One measurement port of the meter was connected, via plastic tubing (through the support strut) to external atmospheric pressure outside the wind tunnel, with the other port, left exposed. The latter port was positioned approximately central to the model, between the side faces. This position was chosen to give the best possible representation of internal pressure magnitude. Wind tunnel static pressure measurements thereafter allowed all data to be referenced to freestream static pressure. The assessed accuracy of pressure measurements was better than $\pm 5 \mathrm{~Pa}\left(\Delta \mathrm{C}_{\mathrm{P}}= \pm 0.004\right)$.

Before and after every test run, a zero, wind-off, data point was taken. This allowed compensation for any thermal drift of measurement zeros during the experiments. For each of the test runs, a yaw angle sweep from $\psi=0^{\circ}$ to $\psi=10.5^{\circ}$, to $\psi=-10.5^{\circ}$, and back to $\psi=0^{\circ}$ (steps of $\psi=3.5^{\circ}$ ) was adopted. All data taken at the same yaw angle was averaged.

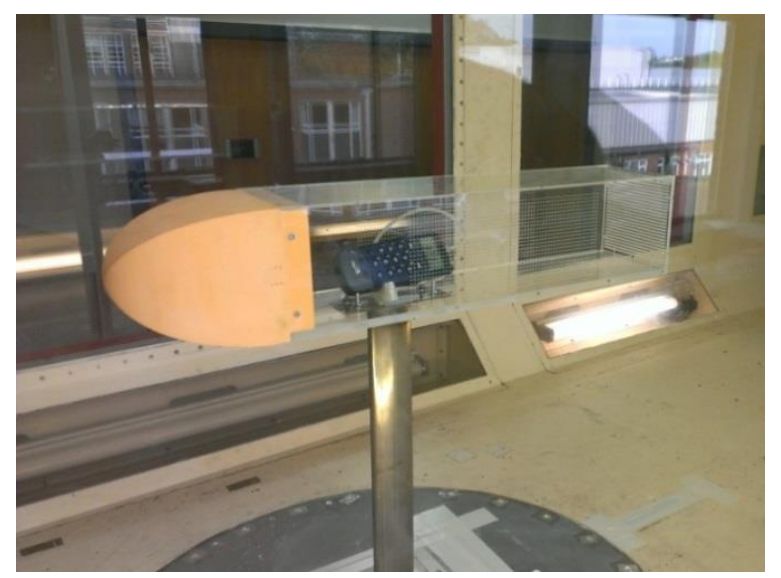

Figure 3. Wind tunnel test set-up with installed internal differential pressure meter. Positive yaw defined as clockwise rotation when viewed from above. Flow direction is from left to right.

\section{Results and Discussion}

Results obtained for $\mathrm{C}_{\mathrm{D}}$ from various side and back face porosity combinations are shown in Figures 4-7. Results are presented by hole diameter combination. For example, ' $1 \mathrm{~S}-4 \mathrm{~B}$ ' represents $1 \mathrm{~mm}$ diameter holes on the side faces (1S), with $4 \mathrm{~mm}$ diameter holes on the back face(4B). For $\psi=0^{\circ}, \mathrm{P}_{\infty}$ was assumed to act on the side faces allowing calculation of $\Delta \mathrm{P}$ s. For $\psi \neq 0^{\circ}, \mathrm{P}_{\infty} \neq$ side face pressure, hence $\Delta \mathrm{P}_{\mathrm{S}}$ is presented referenced to $\mathrm{P}_{\infty}$ for comparison only.

Page 3 of 7 


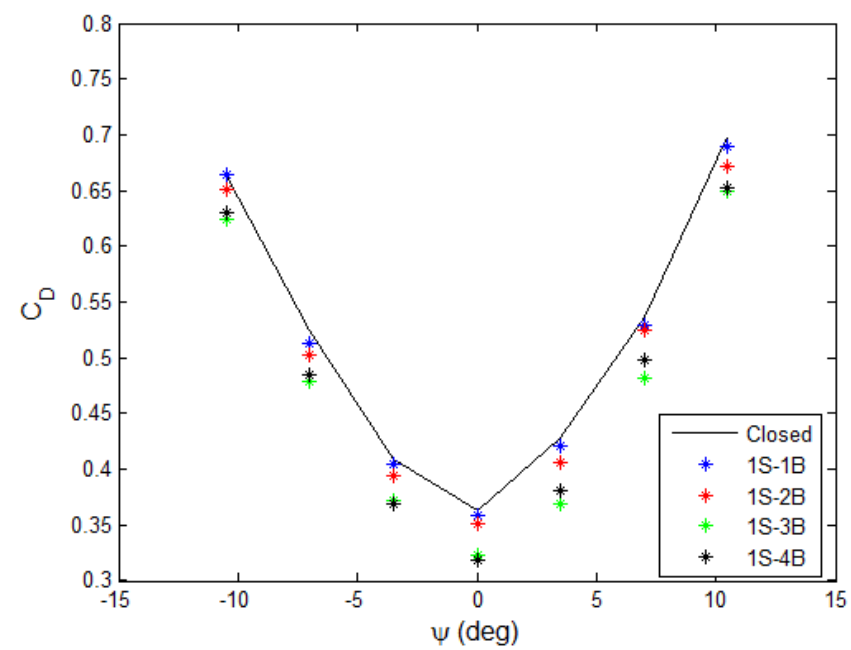

Figure 4. Variation of $C_{D}$ for $1 \mathrm{~mm}$ side face holes.

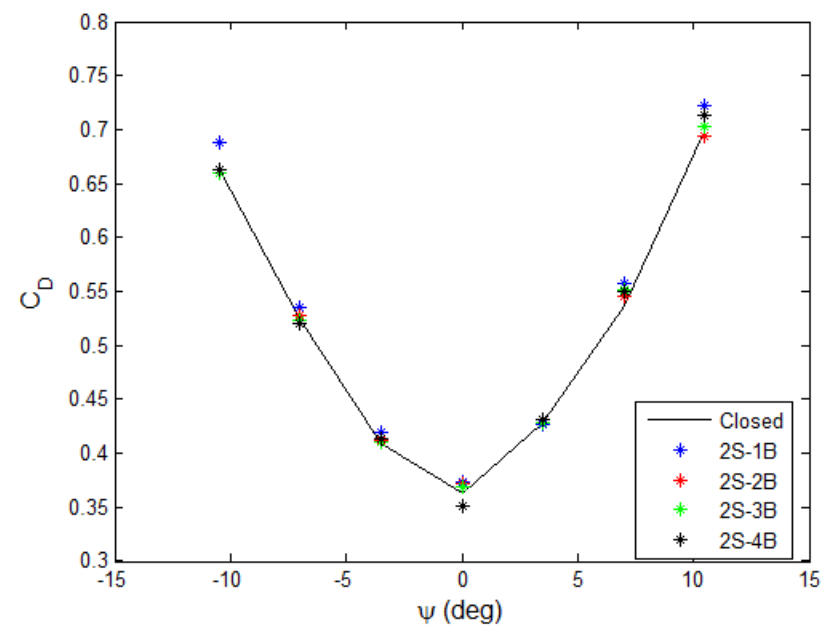

Figure 5. Variation of $\mathrm{C}_{\mathrm{D}}$ for $2 \mathrm{~mm}$ side face holes.

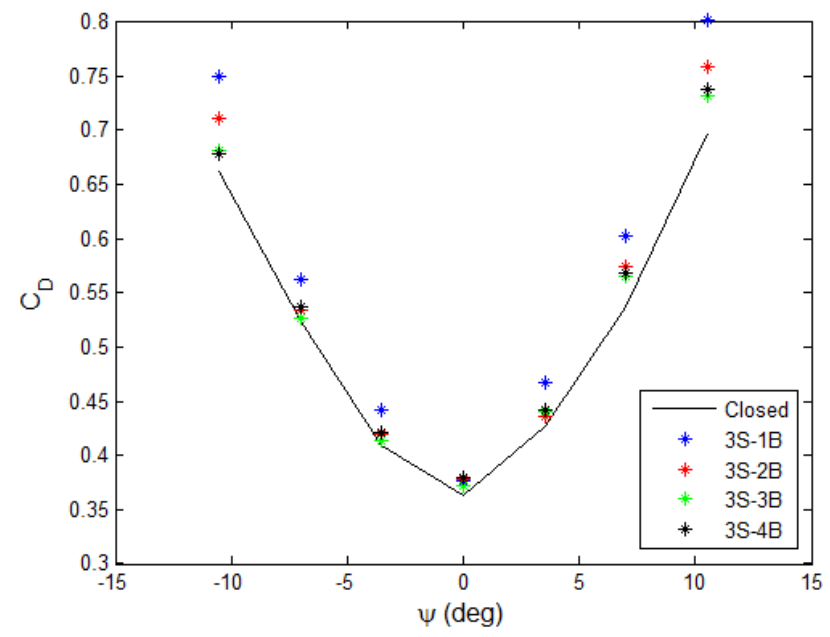

Figure 6. Variation of $\mathrm{C}_{\mathrm{D}}$ for $3 \mathrm{~mm}$ side face holes.

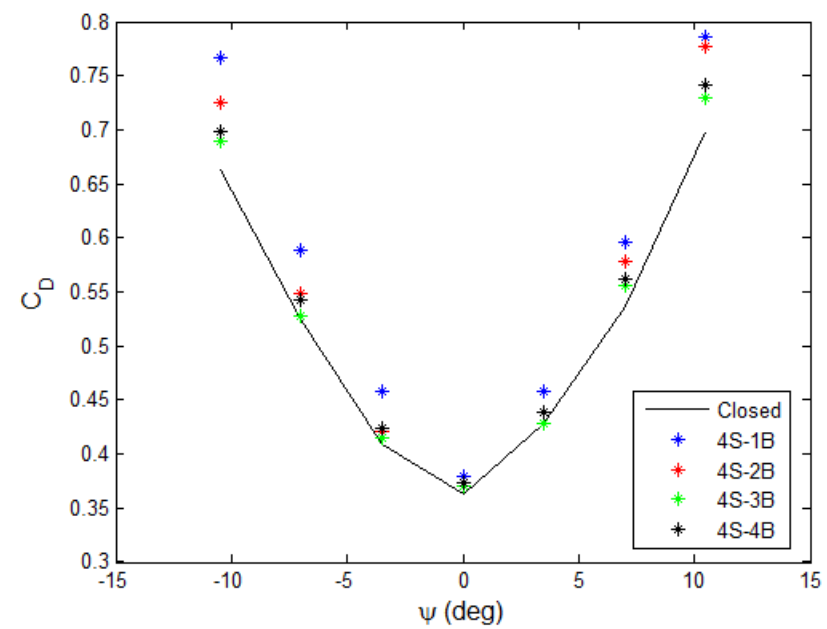

Figure 7. Variation of $\mathrm{C}_{\mathrm{D}}$ for $4 \mathrm{~mm}$ side face holes.

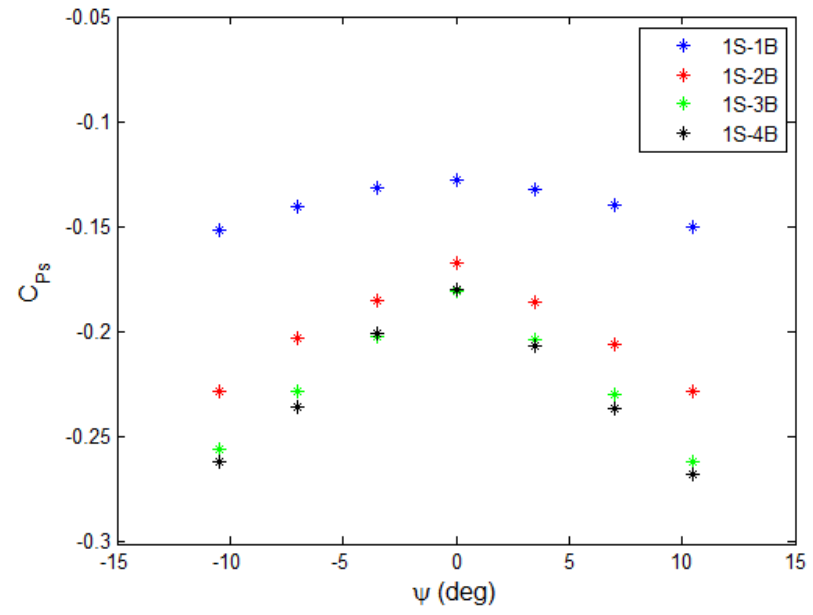

Figure 8. Variation of $\mathrm{C}_{\mathrm{PS}}$ with $1 \mathrm{~mm}$ diameter side face holes.

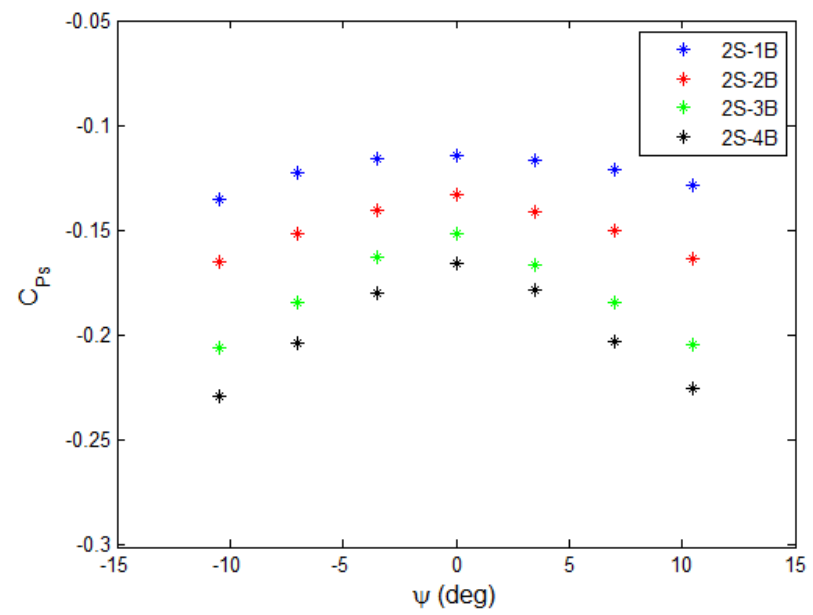

Figure 9. Variation of $\mathrm{C}_{\mathrm{PS}}$ with $2 \mathrm{~mm}$ diameter side face holes.

Page 4 of 7 


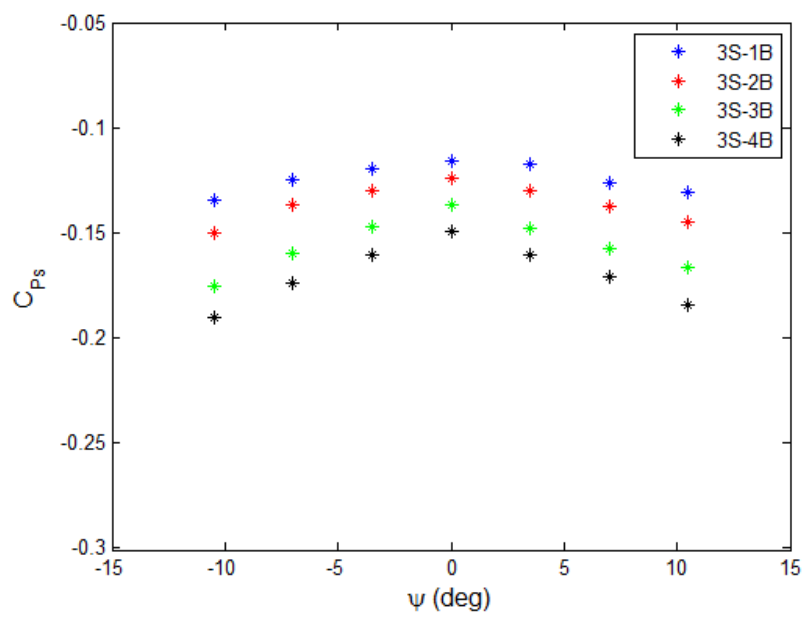

Figure 10. Variation of $\mathrm{C}_{\mathrm{PS}}$ with $3 \mathrm{~mm}$ diameter side face holes.

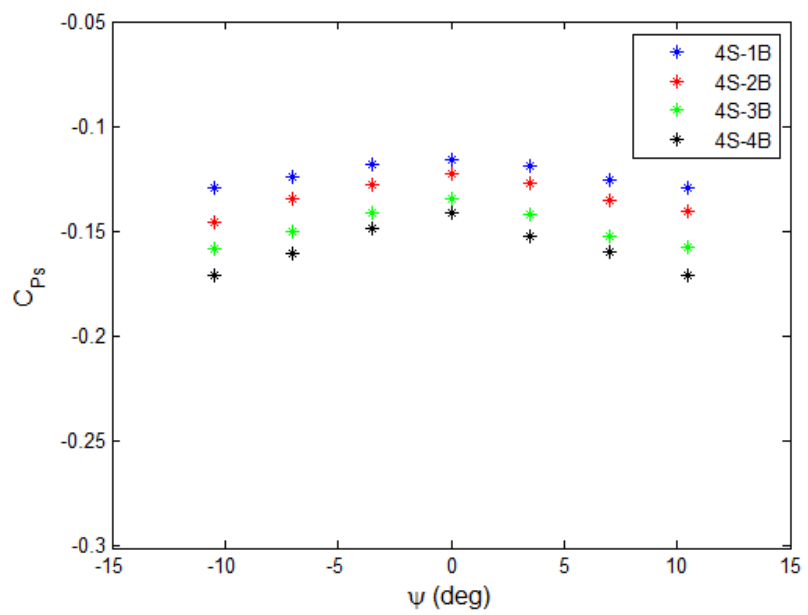

Figure 11. Variation of $\mathrm{C}_{\mathrm{PS}}$ with $4 \mathrm{~mm}$ diameter side face holes.

From Figure 4, results show an almost global reduction in drag for all hole combinations at all yaw angles. For this configuration, the drag reduction is seen to improve with increasing back face hole diameter up to the maximum diameter considered (1S-4B). These results agree generally with findings reported by Mair[9] on configurations using flow injection techniques (no side face porosity), where larger hole diameters in the base region, at low bleed rates, provide the most benefit. Compared to the 'closed' configuration, total reductions of $\Delta \mathrm{C}_{\mathrm{D}} \approx-12 \%$ for $\psi=0^{\circ}$, and $\Delta \mathrm{C}_{\mathrm{D}} \approx-6 \%$ for $\psi=10.5^{\circ}$, were measured.

With increasing side face hole diameter (Figures 5-7), the capability of passive porosity to reduce drag diminishes. From Figure 5 only one combination of hole diameters $(2 \mathrm{~S}-4 \mathrm{~B})$ produced a measureable drag reduction $\left(\Delta C_{D} \approx-3 \%\right)$. All other configurations produced near similar, or greater, drag levels relative to the 'closed' configuration. This suggests an upper limit has been reached. At the largest yaw angle tested $\left(\psi=10.5^{\circ}\right.$ - Figure 5$)$ drag was found to increase by an average of $\Delta C_{D} \approx 3.6 \%$, with no clear trend evident with increasing Dв. Results from Figures 6 and 7 show larger sidewall hole diameters cause further increases, with the largest drag increases occurring at the largest yaw angles. A maximum increase of $\Delta \mathrm{C}_{\mathrm{D}} \approx$ $16 \%$ was found for $4 \mathrm{~S}-1 \mathrm{~B}$ at $\psi=-10.5^{\circ}$.
Figures 8-11 present $\mathrm{C}_{\text {PS }}$ results for various yaw angles and porosity levels. Changes in CPs exhibit near linear trends with applied yaw angle, with decreasing back face hole diameter found to increase $\mathrm{C}_{\mathrm{PS}}$ (for all yaw angles). From Figure 8, a lower limit appears reached for the two largest back face hole diameters $(3 \mathrm{~B}, 4 \mathrm{~B})$. Under these conditions, $\mathrm{C}_{\mathrm{D}}$ is the lowest.

With increase to larger side face hole diameters, overall ranges for $\mathrm{C}_{\mathrm{Ps}}$ magnitudes decrease markedly. Comparing Figure 8, to Figure 11 , increasing the side face hole area by sixteen $(1 \mathrm{~S} \rightarrow 4 \mathrm{~S})$ produces a net decrease in $\mathrm{C}_{\mathrm{PS}}$ range by more than half. This suggests lower speed transpiration flow velocities through the side face, as side face hole diameter increases(conservation of mass).

To assess the performance of the concept, Figures 12 and 13 show combined data for $C_{D}$ and $C_{P S}$ at $\psi=0^{\circ}$ against open area ratio (OAR). As mentioned earlier, for this specific case, to estimate $\mathrm{C}_{\mathrm{PS}}$, the pressure acting on the sides of the model is assumed to be $\mathrm{P}_{\infty}$. From Figure 12, a clear non-linear reduction in drag with increasing OAR exists, reaching a minimum of $\mathrm{C}_{\mathrm{D}}=0.32$ at $\mathrm{OAR}=3.9$. For $\mathrm{OAR}=2.2, \mathrm{C}_{\mathrm{D}}$ remains with experimental uncertainty $\left(\Delta \mathrm{C}_{\mathrm{D}}= \pm 0.02\right)$ at $C_{D}=0.32$, so it should be noted that this result may lie between $2.2<\mathrm{OAR}<3.9$. Figure 13 shows a similar non-linear trend for $\mathrm{C}_{\mathrm{PS}}$ with the lowest magnitudes co-incident with the same range $(2<$ OAR < 4). Coupled together with Figure 14 , which presents $-\Delta \% C_{D}$ against $C_{P S}$, maximum drag reduction appears linked to the lowest values of $\mathrm{CPS}_{\mathrm{PS}}$

To further explore the data obtained for $\psi=0^{\circ}$, Figure 13 and Equations 3-6 were used to estimate various parameters relating to the flow through the side, and back, faces. Some of these relationships are presented in Figure 15, with $\mathrm{C}_{\mathrm{PS}}$, and $\mathrm{C}_{\mathrm{PB}}$, found to vary non-linearly with volumetric flow rate. Using Equation 6, and $\mathrm{C}_{\mathrm{PS}}$ for minimum drag from Figure 13 (CPS at OAR = 2.2 used), $v_{\mathrm{B}}$, $\mathrm{C}_{\mathrm{PB}}$, along with $\mathrm{C}_{\mathrm{Pb}}$ (using Equation 2), and $\mathrm{C}_{\mathrm{q}}$ into the base region, were estimated. Under these conditions, $\mathrm{C}_{\mathrm{PB}}=-0.034, \mathrm{C}_{\mathrm{Pb}}=-0.242$, $v_{B}=6.97 \mathrm{~m} / \mathrm{s}$, and $C_{q}=0.0357$. Comparing these results with previous work on similar models, $\mathrm{C}_{\mathrm{Pb}}$ was found to agree with results presented by Duell \& George[10] and Khalighi,et al[11]. Comparative bleed rates for minimum base pressure conditions are also presented in Mair[9]. Assessment of optimum back and side face porosity levels also showed general agreement with previous work $[1,2,4,8]$ with the combination of $22.1<\varphi_{\mathrm{B}}<39.2$ and $\varphi_{\mathrm{S}} \approx$ $1.3 \%$ for the back, and sides faces respectively (as defined in the current study), within the range showing the largest drag reduction. 


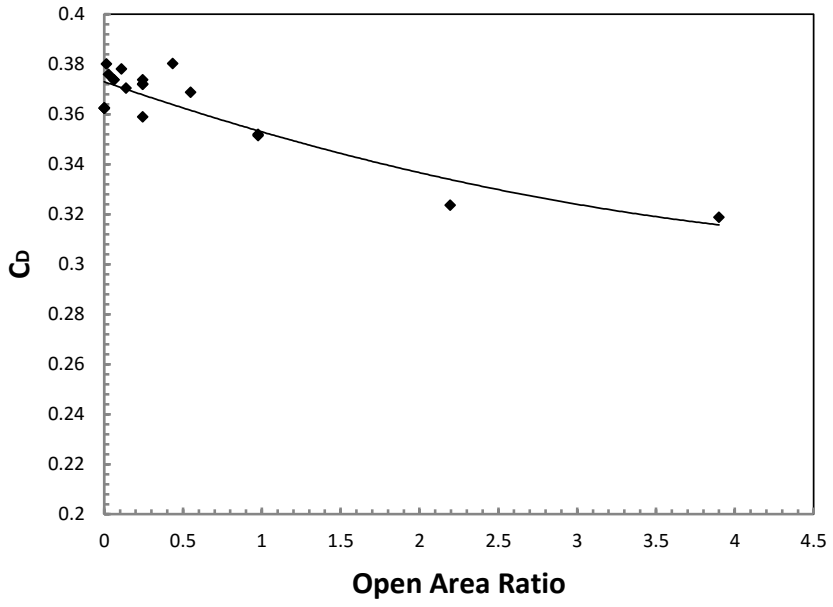

Figure 12. Variation of $C_{D}$ with Open Area Ratio (OAR) for $\psi=0^{\circ}$

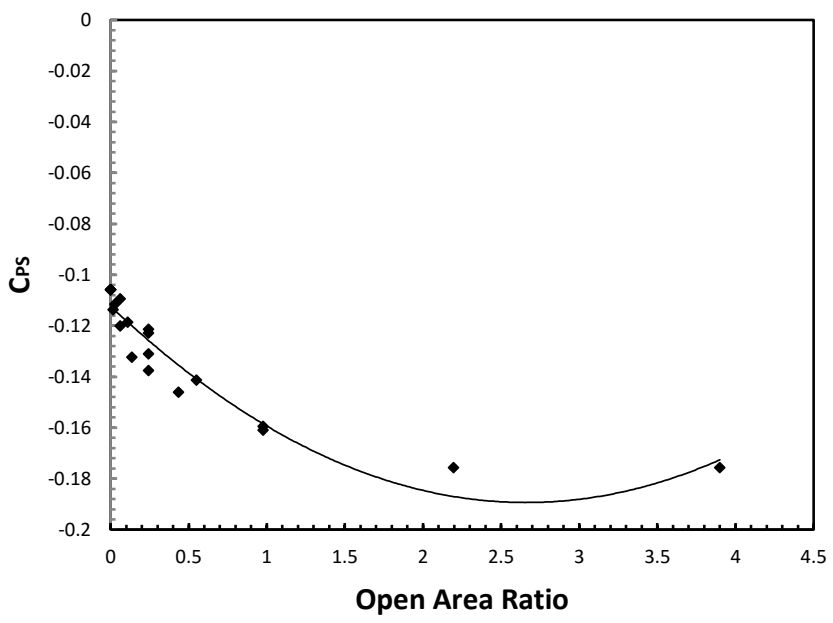

Figure 13. Variation of $\mathrm{C}_{\mathrm{PS}}$ with Open Area Ratio (OAR) for $\psi=0^{\circ}$

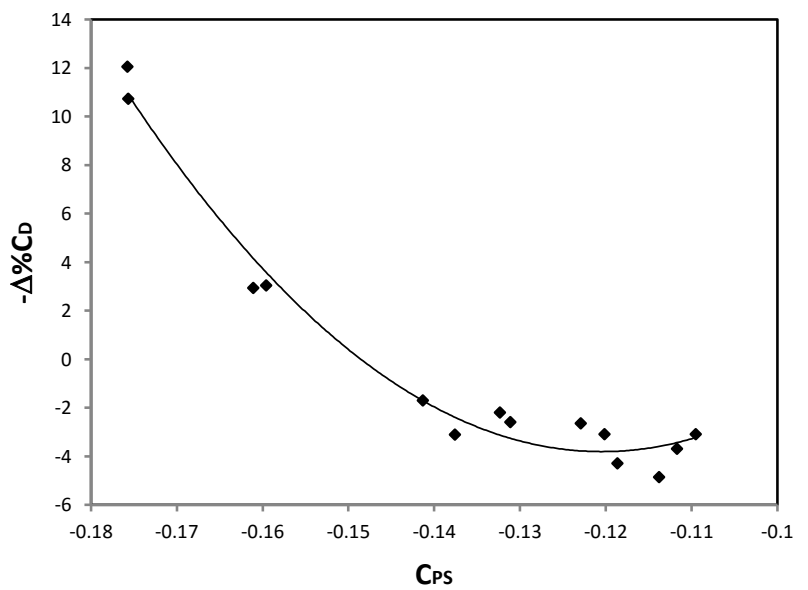

Figure 14. Variation of $-\Delta \% \mathrm{C}_{\mathrm{D}}$ with $\mathrm{C}_{\mathrm{PS}}$ for $\psi=0^{\circ}(1 \mathrm{~S}-2 \mathrm{~S}$ data only).

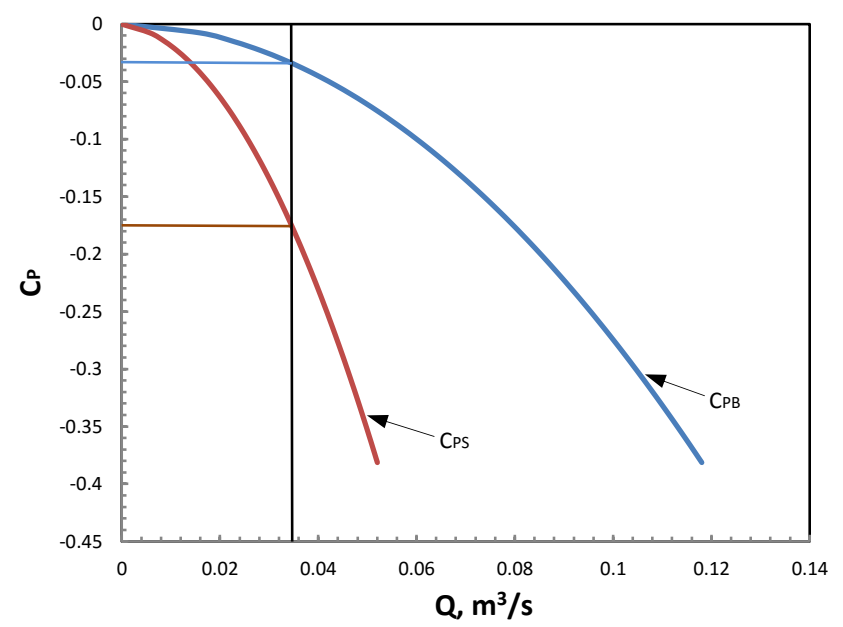

Figure 15. Variation of $\mathrm{C}_{\mathrm{P}}$ with volumetric flow rate, $\mathrm{Q}$, for $\psi=0^{\circ}$

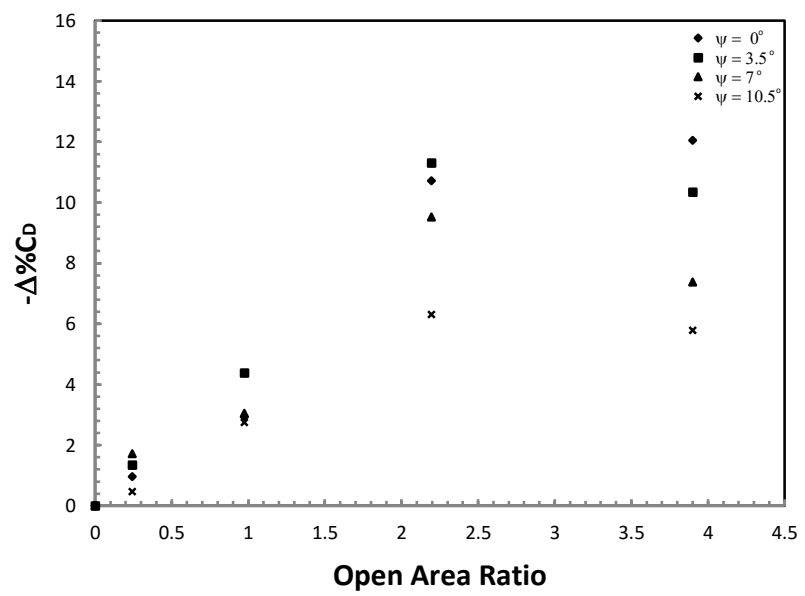

Figure 16. Variation of $-\Delta \% C_{D}$ with Open Area Ratio for different yaw angles.

To assess performance at non-zero yaw angles, Figure 16 shows the capability for $\mathrm{C}_{\mathrm{D}}$ reduction with OAR. For $\psi=0^{\circ}$, optimum OAR was considered likely within the range from $2.2<\mathrm{OAR}<3.9$. For $\psi \neq$ $0^{\circ}$, optimum $\mathrm{OAR}$ is maintained at near $\mathrm{OAR}=2.2$ through the entire non-zero yaw angle range tested. $\mathrm{Up}$ to $\psi \leq 7^{\circ}$ for $\mathrm{OAR}=2.2$, the ability of passive porosity to generate significant $C_{D}$ reduction appears robust with a range of $-9.5 \%<\Delta \mathrm{C}_{\mathrm{D}}<-11.3 \%$. For yaw angles between $3.5^{\circ} \leq \psi \leq 10.5^{\circ}$, drag reduction diminishes for OAR $>2.2$, with the greatest reduction found at $\psi=7^{\circ}$.

\section{Summary/Conclusions}

An experimental investigation into the use of passive porosity as a means for drag reduction on a small-scale bluff-body model has been reported. Various porosity levels, and hole diameters, at yaw angles up to 10.5 degrees, were assessed. The Reynolds number, based on model length, was $2.3 \times 10^{6}$. At zero yaw, use of passive porosity resulted in an overall drag reduction of $12 \%$ when the open area of the back face relative to the side faces was between approximately two and four. Minimum drag for these flow conditions also correlated 
with the largest pressure drop, and transpiration flow velocities, through the side face of the model. Increasing side face porosity level was also found to degrade performance, with the reverse, for back face porosity level, particularly at low side face porosities. For nonzero yaw angles, passive porosity was found to remain effective with the optimal open area ratio reducing to approximately two with a drag benefit of $6 \%$ at 10.5 degrees. Subsequent theoretical analyses, at minimum drag conditions, also showed calculated bleed rate, and base pressure coefficients, in reasonable agreement to other data reported previously.

\section{References}

1. Bauer, S. X. S., and Hemscht, M. J., "Alleviation of Side Force on Tangent-Ogive Forebodies Using Passive Porosity," Journal of Aircraft, 31(2):354-361, 1994, doi: 10.2514/3.46494.

2. Wood, R. M., Banks, D. W., and Bauer, S. X. S., "Passive Porosity with Free and Fixed Separation on a Tangent-Ogive Forebody," Journal of Aircraft, 31(5):1219-1221, 1994, doi: $\underline{10.2514 / 3.46635}$

3. Nagamatsu, H. T., Orozco, R. D., Ling, D. C., "Porosity Effect on Supercritical Airfoil Drag Reduction by Shock Wave Boundary Layer Control," presented at AIAA Fluid Dynamics, Plasma Dynamics, and Lasers Conference, USA, June 25-27, 1984.

4. Hunter, C.A., Viken, S.A., Wood, R.M., and Bauer S.X.S., "Advanced Aerodynamic Design of Passive Porosity Control Effectors," presented at $39^{\text {th }}$ AIAA Aerospace Sciences Meeting, USA, January 8-11, 2001.

5. Wood, R. and Bauer, S., "Advanced Aerodynamic Control Effectors," SAE Technical Paper 1999-01-5619, 1999, doi: 10.4271/1999-01-5619.

6. Frink, N., Bauer, S.X.S., and Hunter, C.A., "Simulation of Flows with Passive Porosity," presented at 23rd International Congress of Aeronautical Sciences, 8-13 September, Canada, 2002.

7. Wood, R., "Impact of Advanced Aerodynamic Technology on Transportation Energy Consumption," SAE Technical Paper 2004-01-1306, 2004, doi: 10.4271/2004-01-1306.

8. Bauer, S. X. S., and Wood, R. M., "Base Passive Porosity for Vehicle Drag Reduction," US Patent 6,616,218, September 9, 2003.

9. Mair, W.A., "Drag Reduction Techniques for Axi-Symmetric Bluff Bodies," in Aerodynamic Drag Mechanisms of Bluff Bodies and Road Vehicles, (Plenum, New York, 1978), 161178, doi: 10.1007/978-1-4684-8434-2.

10. Duell, E. G., and George, A. R., "Experimental Study of a Ground Vehicle Body Unsteady Near Wake," SAE Technical paper 1999-01-0812, 1999, doi: 10.4271/1999-01-0812.

11. Khalighi, B., Zhang, S., Koromilas, C. et al, "Experimental and Computational Study of Unsteady Wake Flow Behind a Bluff Body with a Drag Reduction Device," SAE paper 2001-011042, 2001, doi: 10.4271/2001-01-1042.

12. Kraushaar, S. L., and Chokani, N., "Improved Models for the Porous Surface with Passive Control," NASA Technical Report, 19990064146, Jan 01, 1996.

13. Poll, D., and Danks, M., "The Aerodynamic Performance of Laser Drilled Sheets," STAR, (31):274-277, 1993.

14. RAMPF, “Tooling Solutions," http://www.rampfgroup.com/products-solutions/tooling-solutions/, accessed Sept. 2017.

15. HINDLEYS, "Perspex and Design Materials," https://www.hindleys.com/index.php/perspec-design-materials/, accessed Sept. 2017.
16. Schlichting, H., and Gersten, K., "Boundary Layer Theory, $7^{\text {th }}$ Edition" (Springer, Berlin, 2003), 536-542, ISBN 0070553343

17. Aerospace Technology Institute, "UK Wind Tunnels," http://www.ati.org.uk/aerodynamics/facilities/markham-windtunnel-26/, accessed Sept. 2017.

18. AMTI, "MC3A Force/Torque Sensor," http://www.amti.uk.com/products/mc3a-6-axis-force-andtorque-sensor.php, accessed Sept. 2017.

19. AMTI, "DSA-6 Digital strain gauge amplifier," http://downloadcentral.interfaceforce.co.uk/downloads/DSA$\underline{6 . p d f}$

20. Digitron, "2000 Series Manometer," http://www.digitron.com/media/import/2000\%20Pressure\%20U nbranded\%20XG0781\%20rev4.pdf, accessed Sept. 2017.

\section{Nomenclature}

As, $\mathbf{A}_{\mathbf{B}}$ Individual hole area, $\pi \mathrm{D}^{2} / 4, \mathrm{~m}^{2}$.

w Model width, $\mathrm{m}$.

b Model side face length without the nose, $m$.

CD Drag Coefficient, $\mathrm{D}_{\mathrm{f}} /(\mathrm{qwh})$.

$\mathrm{C}_{\mathbf{P S}} \quad$ Differential pressure coefficient for the side face, $\left(\mathrm{P}-\mathrm{P}_{\infty}\right) / \mathrm{q}$.

CPB Differential pressure coefficient for the back face, $\left(\mathrm{P}_{\mathrm{b}}-\mathrm{P}\right) / \mathrm{q}$.

$\mathbf{C}_{\mathbf{P b}} \quad$ Base pressure co-efficient, $\left(\mathrm{P}_{\mathrm{b}}-\mathrm{P}_{\infty}\right) / \mathrm{q}$.

$\mathbf{C}_{\mathbf{P}} \quad$ Pressure co-efficient.

$\mathbf{C}_{\mathbf{q}} \quad$ Volumetric flow rate coefficient, $\mathrm{Q} /\left(\mathrm{whV}_{\infty}\right)$.

D Generic designation for hole Diameter, $\mathrm{m}$

Df Drag force, $\mathrm{kgms}^{-2}$.

Ds, DB Diameter of holes in side and back faces respectively, $\mathrm{m}$.

h Height of model, $\mathrm{m}$.

I Length of model, $\mathrm{m}$

L Generic designation for hole length, $m$

$\mathbf{L}_{\mathbf{S}}, \mathbf{L}_{\mathbf{B}} \quad$ Hole length in the side and back faces respectively, $\mathrm{m}$.

$\mathbf{N}_{\mathbf{S}}, \mathbf{N}_{\mathbf{B}} \quad$ Total number of holes in side(both) and back faces

OAS Open area of the side faces, $\mathrm{N}_{\mathrm{s}} \mathrm{As}_{\mathrm{s}}$.

OAB Open area of the back face, $\mathrm{N}_{B} \mathrm{~A}_{\mathrm{B}}$.

OAR Open area ratio. OAB/OAS.

$\mathbf{P}_{\infty}, \mathbf{P}, \mathbf{P}_{\mathbf{b}}$ Wind tunnel static, Internal plenum, and model base pressures respectively, $\mathrm{kgm}^{-1} \mathrm{~s}^{-2}$.

q Dynamic pressure, $\mathrm{kgms}^{-2}$.

Q Volumetric flow rate, $\mathrm{m}^{3} \mathrm{~s}^{-1}$.

Ren $_{\text {n }} \quad$ Reynolds number, based on model length, $\left(\rho V_{\infty} 1\right) / \mu$.

$\mathbf{V}_{\infty} \quad$ Freestream velocity, $\mathrm{ms}^{-1}$

$v$ Generic designation for transpiration velocity, $\mathrm{ms}^{-1}$

$\mathbf{v}_{\mathbf{S}}, \boldsymbol{v}_{\mathbf{B}}$ Transpiration velocities through side and back faces, $\mathrm{ms}^{-1}$

$\Delta \mathbf{P}_{\mathbf{S}} \quad$ Side face to plenum pressure difference, $\mathrm{Pa}$.

$\Delta \mathbf{P}_{\mathbf{B}} \quad$ Plenum to the back face pressure difference, $\mathrm{Pa}$.

$\varphi s \quad$ Porosity fraction of side faces, $\mathrm{N}_{\mathrm{S}} \mathrm{A}_{\mathrm{S}} / 2 \mathrm{bh}$.

$\varphi \quad$ Porosity fraction of back face, $\mathrm{N}_{\mathrm{B}} \mathrm{A}_{\mathrm{B}} /$ wh.

$\mu \quad$ Absolute viscosity, $\mathrm{kgms}^{-1}$

$\rho \quad$ Density, $\mathrm{kgm}^{-3}$

\section{Contact Information}

Dr Alvin Gatto

College of Engineering, Design, and Physical Sciences, Brunel University London, Uxbridge, Middlesex, UB8 3PH, UK Email: alvin.gatto@brunel.ac.uk.

Professor Holger Babinsky

Centre for Sustainable Road Freight

Engineering Department, University of Cambridge,

Cambridge, England, CB2 1PZ, UK.

Email: $\underline{\text { hb@eng.cam.ac.uk }}$

Page 7 of 7 